\title{
ANALISA KEAMANAN WEB SERVER TERHADAP SERANGAN POSSIBILITY SQL INJECTION Studi Kasus: Web Server UMK
}

\author{
Yuni Wardatul Indriani \\ 185100055 \\ Fakultas Komputer \\ yuniwardatul.student@umitra.ac.id
}

\begin{abstract}
Informasi sangatlah dibutuhkan dalam kehidupan, untuk mendapatkan informasi dan bertukar informasi sangatlah mudah untuk dilakukan kapan saja dan dimana saja. Informasi meliputi file dan data, jaringan komputer merupakan salah satu hal yang penting untuk pertukaran informasi. Salah satu media yang dapat digunakan adalah FTP (File Transfer Protocol) yaitu aplikasi untuk tukar menukar data antara client dengan server dalam satu jaringan, dengan cara client mengupload file yang tersimpan di hard disk server dan dapat diakses selama client terhubung dengan jaringan internet.

Seiring berkembangnya teknologi saat ini file penting yang diupload dan didownload sangat rentan dengan kejahatan dunia internet seperti tool wireshark yang dapat mengetahuiusername, password, dan file yang diupload dan didownload oleh client. Maka dari itu dibuatlah FTP server dengan sistem keamanan transfer data. FTP server yang telah diaktifkan fitur TLS (Transfer Layer Security) dapat mengamankan informasi username, password, dan file yang diupload dan didownload oleh client tidak dapat dibaca oleh tool wireshark.

Dalam mencegah penuhnya kapasitas hard disk server, maka digunakanlah Disk Quota yang berfungsi untuk memberikan batasan kuota client dalam melakukan upload. Dengan demikian FTP server yang belum menggunakan TLS maka username, password dan file dapat dibaca oleh tool wireshark. Sedangkan FTP server yang telah menggunakan TLS lebih aman karena username, password dan file tidak dibaca oleh tool wireshark.
\end{abstract}

Kata Kunci : Disk Quota, File Transfer Protocol,(TLS) Transfer Layer Security. 


\section{A. PENDAHULUAN}

Perkembangan teknologi yang semakin canggih memungkinkan proses kegiatan berjalan sangat cepat. Hadirnya teknologi membuat pekerjaan semain mudah.Kemudahan yang ditawarkan teknologi tentunya seiring-seirama dengan bahaya yang dapat disisipkan melalui berbagai hal.Terlebih, jika bahaya tersebut tersistem sehingga kecenderungan pengguna tidak menyadarinya dengan adanya bahaya yang sudah masuk dan mengintainya. Sistem dapat didefinisikan sebagai seperangkat komponen (sumber daya) terkait, dengan batas yang jelas dan bekerjasama untuk mencapai tujuan tertentu melalui sebuah inputan dalam proses transfromasi yang teroganisir (Brien dan Marakas, 2010).Sedangkan Sistem Informasi lebih menekankan pada pengelolaan sumber daya (resource) yang adamenjadi produk informasi. Website UMK (Universitas Muria Kudus) dengan domain umk.ac.id merupakan website yang digunakan sebagai media dan sarana informasi kampus. Mengingat website ini dapat diakses secara luas, maka dinilai perlu memperhatikan keamanan website. Terdapat beberapa cara yang dapat digunakan untuk melakukan pengujian terhadap kemanan website. Salah satunya adalah dengan melakukan SQL Injection.

SQL injection adalah kerentanan yang terjadi ketika penyerang memiliki kemampuan untuk mempengaruhi Structured Query Language (SQL) query yang melewati suatu aplikasi ke databaseback-end. Dengan mampu mempengaruhi apa yang akan diteruskan ke database, penyerang dapat memanfaatkan sintaks dan kemampuan dari SQL, serta kekuatan dan fleksibilitas untuk mendukung fungsi operasi database dan fungsionalitas sistem yang tersedia ke database. Injeksi SQL bukan merupakan kerentanan yang eksklusif mempengaruhi aplikasi Web, kode yang menerima masukan dari sumber yang tidak dipercaya dan kemudian menggunakan input yang membentuk SQL dinamis bisa rentan (Clarke, 2009). Kasus SQL Injection terjadi ketika seorang penyerang dapat memasukkan serangkaian pernyataan SQL ke query dengan memanipulasi data input ke aplikasi (Anley, 2002).

\section{B. PEMBAHASAN / STUDI KASUS}

\section{Implementasi Penelitian}

Pada implementasi penelitian kali ini dilaksanakan oleh tim peneliti internal program studi Teknik Informatika, Fakultas Teknik Universitas Muria Kudus. Objek penelitian dikerjakan di UPT Perencanaan Sistem Informasi (UPT PSI) Universitas Muria Kudus dengan melibatkan tim teknis UPTPSI, dalam hal ini administrator jaringan(network engineer).

Kegiatan awal penelitian ini adalah dengan diintegrasikannya intruder detection systems (IDS) tools (snort) yang dipasang melalui komputer server PSI UMK pada tanggal 31 Maret 2015 s/d 10 April 2015 (gambar 1). Selanjutnya, hasil paket-paket data yang masuk melalui IDS tools (Snort) di evalusi dan di jelaskan kedalam laporan.

Dalam pelaksanaan kegiatan penelitian ini telah dilakukan identifikasi kebutuhan awal perangkat keras dan perangkat lunak sebagai berikut:

1) Kebutuhan perangkat keras (hardware)

- Server Web UMK

2) Kebutuhan perangkat lunak (software)

- Opensource IDS (Snort)

- Internet

- Linux OS (operating systems)

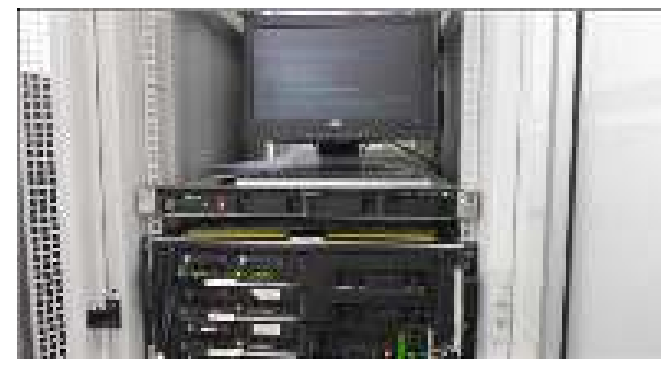




\section{Section 01}

Gambar 1. Komputer server yang telah terpasang IDS (Snort)

\section{Disain Analisa dan Topologi Jaringan}

Sebelum penelitian di implementasikan, perlu dibangun sebuah perencanaan yang nantinya membantu memudahkan jalannya proses pelaksanaan identifikasi pada penelitian. Kegiatan ini biasanya disebut sebagai analisa disain topologi (topology design). Pada analisa ini terlibat komponen perangkat yang saling berhubungan, yaitu: jaringan internet, IDS Snort sebagai sistem pendeteksi data yang digunakan mengidentifikasi seluruh aktivitas penyadap (intruder) yang masuk ke Server Web UMK (gambar. 2).

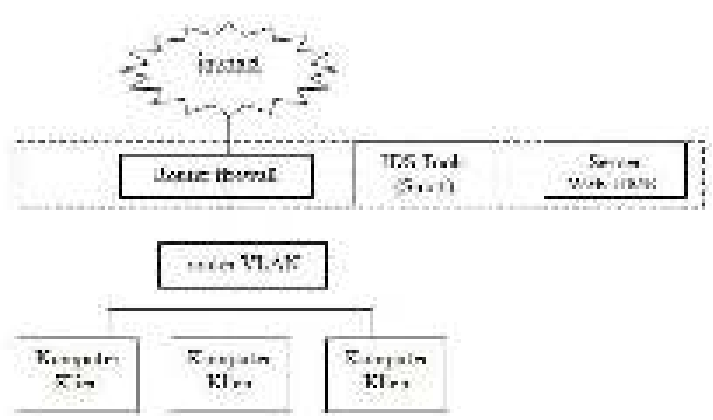

Gambar 2. Topologi jaringan analisa IDS

Snort

Skema yang ditunjukkan pada gambar 2, paket data berawal masuk melalui komputer Client yang masuk dan ingin mengkases server UMK. Setelah itu paket data akan melewati router firewall yang berfungsi meneruskan (forwarding) informasi yang akan dituju. Selanjutnya, melalui IDS Snort inilah sumber informasi akan di deteksi apakah sebagai paket data yang baik atau tidak, dalam istilah jaringan disebut sebagai alert.IDS (intrusion detection systems) pada prinsipnya sebagai sebuah perangkat yang didisain khusus untuk mengidentifikasi seluruh aktivitas (paket data) yang masuk di jaringan internet.Teknologi IDS ini telah dilengkapi beberapa komponen (software) yang handal, seperti packet decoder, preprocessor or input plugins, detection engine, loging and alerting systems dan output modules (tabel 1).
Tabel 1. Komponen-komponenIDS

\begin{tabular}{|c|c|c|}
\hline No & Nama & Deskripsi \\
\hline 1 & $\begin{array}{l}\text { Packet } \\
\text { decoder }\end{array}$ & $\begin{array}{l}\text { Memproses paket-paket } \\
\text { data yang masuk }\end{array}$ \\
\hline 2 & $\begin{array}{l}\text { Preprocessor } \\
\text { dan Plugins }\end{array}$ & $\begin{array}{l}\text { Input Perangkat } \\
\text { tambahan yang terpasang } \\
\text { di IDS untuk mengenali } \\
\text { data yang masuk diluar } \\
\text { protokol yang ada }\end{array}$ \\
\hline 3 & $\begin{array}{l}\text { Detection } \\
\text { engine }\end{array}$ & $\begin{array}{l}\text { Mengaplikasikan rule ke } \\
\text { paket data yang masuk }\end{array}$ \\
\hline 4 & $\begin{array}{l}\text { Loging and } \\
\text { alerting } \\
\text { system }\end{array}$ & $\begin{array}{l}\text { Pemrosesan pesan log } \\
\text { dan tanda-tanda yang } \\
\text { berbahaya (tidak } \\
\text { dikenali) pada jaringan }\end{array}$ \\
\hline 5 & $\begin{array}{l}\text { Output } \\
\text { modules }\end{array}$ & $\begin{array}{l}\text { Memproses paket data } \\
\text { yang masuk sesuai } \\
\text { dengan klasifikasi pesan } \\
\text { (signature) } \\
\text { menampilkan hasilnya }\end{array}$ \\
\hline
\end{tabular}

\section{ID SECURITY}

\section{QWTD4452377-ASP-5244166}

\section{KESIMPULAN}

Berdasarkan pembahasan maka pada penelitian ini dapat disimpulkan bahwa :

1. Pada Web Server Universitas Muria Kudus (UMK) terdapat beberapa aktifitas yang berusaha masuk ke sistem jaringan melalui notifikasi alert IDS Snort (ping), meskipun aktifitas tersebut hanya sekedar melihat-lihat web yang aktif, namun kegiatan ini perlu di waspadai.

2. Dengan adanya IDS Snort, seluruh aktifitas jaringan yang berjalan di web server UMK dapat dipantau setiap saat.

3. Pemberian aturan snort/ rule yang sebagai alternatif yang dapat memberikan peringatan dari serangan (intruder) yang masuk ke jaringan.

4. Secara umum dengan menggunakan IDS Snort sebagai pemantau jaringan dapat 


\section{Section 01}

disimpulkan bahwa web server UMK dapat dikatakan relatif aman.

\section{E. DISKUSI}

Saya bersama teman saya Intan mendiskusikan dengan baik Hasil analisis implementasi Kasus SQL Injection terjadi ketika seorang penyerang dapat memasukkan serangkaian pernyataan sql ke query dengan memanipulasi data input ke aplikasidapat disimpulkan sebagai berikut.

1. Dapat dikatakan bahwa serangan SQL Injection sangat berbahaya karena penyerang yang telah berhasil memasuki database sistem dapat melakukan manipulasi data yang ada pada database sistem. Proses manipulasi data yang tidak semestinya oleh penyerang dapat menimbulkan kerugian bagi pemilik website yang terinjeksi.

2. Keamanan data dan informasi sangat penting dalam menjaga ketahanan sebuah website. Berdasarkan uraianuraian tersebut, maka dinilai perlu untuk menguji kemanan website UMK terhadap serangan SQL Injection, serta melakukan analisa terhadap kelemahan sistem yang ada, sehingga dapat diperoleh tindakan selanjutnya untuk perbaikan sistem.

\section{F. REFERENCE}

[1] O. M. Febriani and A. S. Putra, "Sistem Informasi Monitoring Inventori Barang Pada Balai Riset Standardisasi Industri Bandar Lampung," J. Inform., vol. 13, no. 1, pp. 90-98, 2014.

[2] A. S. Putra, "Paperplain: Execution Fundamental Create Application With Borland Delphi 7.0 University Of Mitra Indonesia," 2018.
[3] A. S. Putra, "2018 Artikel Struktur Data, Audit Dan Jaringan Komputer," 2018.

[4] A. S. Putra, "ALIAS MANAGER USED IN DATABASE DESKTOP STUDI CASE DB DEMOS."

[5] A. S. Putra,"COMPREHENSIVE SET OFPROFESSIONAL FOR DISTRIBUTE COMPUTING."

[6]A. S. Putra "DATAORIENTED RECOGNITION IN BORLAND DELPHI 7.0."

[7] A. S. Putra, "EMBARCADERO DELPHI XE 2 IN GPU-POWERED FIREMONKEY APPLICATION."

[8] A. S. Putra, "HAK ATAS KEKAYAAN INTELEKTUAL DALAM DUNIA TEKNOLOGY BERBASIS REVOLUSI INDUSTRI 4.0.”

[9] A. S. Putra, "IMPLEMENTASI PERATURAN PERUNDANGAN UU. NO 31 TAHUN 2000 TENTANG DESAIN INDUSTRI BERBASIS INFORMATION TECHNOLOGY."

[10] A.S.Putra, "IMPLEMENTATION OF PARADOX DBASE."

[11] A. S. Putra, "IMPLEMENTATION OF TRADE SECRET CASE STUDY SAMSUNG MOBILE PHONE."

[12] A. S. Putra, "IMPLEMENTATION PATENT FOR APPLICATION WEB BASED CASE STUDI WWW. PUBLIKLAMPUNG. COM."

[13] A.S.Putra, "IMPLEMENTATION SYSTEM FIRST TO INVENT IN DIGITALLY INDUSTRY."

[14] A. S. Putra, "MANUAL REPORT \& INTEGRATED DEVELOPMENT ENVIRONMENT BORLAND DELPHI 7.0.” 


\section{Section 01}

[15] A. S. Putra, "PATENT AS RELEVAN SUPPORT RESEARCH.”

[16] A. S. Putra, "PATENT FOR RESEARCH STUDY CASE OF APPLE. Inc."

[17] A. S. Putra, "PATENT PROTECTION FOR APPLICATION INVENT."

[18] A. S. Putra, "QUICK REPORT

[19] IN PROPERTY PROGRAMMING.”

[20] A. S. Putra, "REVIEW CIRCUIT LAYOUT COMPONENT REQUIREMENT ON ASUS NOTEBOOK."

[21] A. S. Putra, "REVIEW TRADEMARK PATENT FOR INDUSTRIAL TECHNOLOGY BASED 4.0.”

[22] A. S. Putra, "TOOLBAR COMPONENT PALLETTE IN OBJECT ORIENTED PROGRAMMING."

[22] A. S. Putra, "WORKING DIRECTORY SET FOR PARADOX 7."

[23] A. S. Putra, "ZQUERY CONNECTION IMPLEMENTED PROGRAMMING STUDI CASE PT. BANK BCA Tbk."

[24] A. S. Putra, D. R. Aryanti, and I. Hartati, "Metode SAW (Simple Additive Weighting) sebagai Sistem Pendukung Keputusan Guru Berprestasi (Studi Kasus: SMK Global Surya)," in Prosiding Seminar Nasional Darmajaya, 2018, vol. 1, no. 1, pp. 85-97.

[25] A. S. Putra and O. M. Febriani, "Knowledge Management Online Application in PDAM Lampung Province," in ProsidingInternational conference on Information Technology and Business (ICITB), 2018, pp. 181-187.

[26] A. S. Putra, O. M. Febriani, and B. Bachry, "Implementasi Genetic Fuzzy System Untuk Mengidentifikasi Hasil Curian Kendaraan Bermotor Di Polda Lampung,"
SIMADA (Jurnal Sist. Inf. dan Manaj. Basis Data), vol. 1, no. 1, pp. 21-30, 2018.

[27] A. S. Putra, H. Sukri, and K. Zuhri, "Sistem Monitoring Realtime Jaringan Irigasi Desa (JIDES) Dengan Konsep Jaringan Sensor Nirkabel," IJEIS (Indonesian J. Electron. Instrum. Syst., vol. 8, no. 2, pp. 221-232.

[28] D. P. Sari, O. M. Febriani, and A. S. Putra, "Perancangan Sistem Informasi SDM Berprestasi pada SD Global Surya," in Prosiding Seminar Nasional Darmajaya, 2018, vol. 1, no. 1, pp. 289-294. 